\title{
Synthesis, Spectroscopic, Intramolecular Energy Transfer and Electronic Structure Nonlinear Optical Properties of Novel Tetrahydropyrimidinone
}

\section{UKKARAMOORTHY UMADEVI ${ }^{1}$, ARUMUGAM DHANDAPANI ${ }^{2}$, SUBRAMANIYAN MANIVARMAN ${ }^{1 *}$ and SUBRAMANIYAN SUBASHCHANDRABOSE ${ }^{3}$}

\author{
${ }^{1} P G$ \& Research Department of Chemistry, Government Arts College, C-Mutlur, \\ Chidambaram 608102, Tamil Nadu, India. \\ ${ }^{2}$ Department of Chemistry, CK College of Engineering and Technology, Cuddalore 600003 , \\ Tamil Nadu, India. \\ ${ }^{3}$ Centre for Functionalized Magnetic Materials (FunMagMa), Immanuel Kant Baltic Federal University \\ 236041, Kaliningrad, Russia. \\ *Corresponding author E-mail: drsmgac@gmail.com \\ http://dx.doi.org/10.13005/ojc/340304
}

(Received: November 28, 2017; Accepted: May 17, 2018)

\begin{abstract}
New oxygen bridged tricyclic pyrimidinone molecule is synthesized by Biginelli condensation reaction using $\mathrm{CeCl}_{3} \cdot 7 \mathrm{H}_{2} \mathrm{O}$ as an efficient catalyst. The new molecular structural arrangement of unusual product of Biginelli reaction is analysed using experimental and theoretical techniques. The extent of intermolecular charge transfer and delocalization are estimated and discussed in terms of natural bond orbitals. The optimized geometry reveals the intramolecular hydrogen bonding exists in the studied compound and it is confirmed using NBO analysis. The shifts in vibrational wavenumber due to the hydrogen bondings are curiously analysed with potential energy distributions of vibrations. To scrutinize the nonlinear optical properties of the title molecule first order hyperpolarizability components are calculated and its shows the title molecule is promising candidate for NLO studies. In addition, the active charge sites and energy gap are also identified and discussed.
\end{abstract}

Keywords: THPC, Hydrogen-bonding's, Donor-acceptor interactions, NLO, MEP.

\section{INTRODUCTION}

Dihydropyrimidinones (DHPM) and their derivatives have gained greater attention in synthetic and material chemistry, because of their wide range of pharmacological and optical activities ${ }^{1,2}$.
Recently, strong photo physical and electrochemical active materials were reported with a series of pyrimidine-carbazole conjugates ${ }^{3}$. Pyridine-5carboxylic acid was used as an anchoring group in solar cells with an efficiency of $5.5 \% 4$. Interestingly the organic molecules with donor and acceptor

This is an Open Access article licensed under a Creative Commons Attribution-Non Commercial-Share Alike 4.0 International License (https://creativecommons.org/licenses/by-nc-sa/4.0/), which permits unrestricted Non Commercial use, distribution and reproduction in any medium, provided the original work is properly cited. 
groups connected with $\pi$-conjugation have shown wide range of field effect transistor, organic light emitting diodes (OLED), dye-sensitized solar cells (DSSCs) and nonlinear optics ${ }^{5-8}$. In recent years, the direct conversion of solar energy has gained more attention in terms of low cost and higher efficiency in DSSC .

Biginelli compounds contained multiple functional groups where a significant conformational flexibility was found between the aryl and the ester moiety. Dihydropyrimidinones and its corresponding derivatives are acted as vital hetero cyclic entities that possess diverse pharmacological and therapeutic properties, such as anti-inflammatory, anti-viral, anti-microbial and anti-tumour activities ${ }^{10}$. Moreover these compounds had emerged as $\alpha$-adreno receptor antagonists, calcium channel blockers and anti-hypertensive agents ${ }^{11}$. Due to our interest in the Biginelli reaction, in the current manuscript, we intend to evaluate the molecular structural arrangement, shifting in wavenumbers, energy transfer occurring intramolecular level and nonlinear optical investigation for the newly synthesized oxygen bridged Biginelli compound with theoretical predictions. We intend this manuscript to be very useful for the optical investigations of unexpected product of the Biginelli condensation. The new structural arrangement of ethyl-2-(chloromethyl)9-methoxy-4-oxo-3, 4,5,6-tetrahydro-2H-2,6methanobenzo[g] ${ }^{1,3,5}$ oxadiazocine-11-carboxylate (THPC) has been studied experimentally as well as with theoretical calculations. In addition, the vertical excitations in electronic states and identification of active sites in novel THPC also carried out.

\section{EXPERIMENTAL}

\section{Synthesis of novel oxygen bridged tetrahydropyrimidinone (THPC)}

Ethanolic solution of urea $(0.9 \mathrm{~g})$ and 4-methoxysalicylaldehyde $(0.76 \mathrm{~g})$ is mixed to ethyl-4-chloroacetoacetate $(0.82 \mathrm{ml})$. To this homogenous mixture $0.465 \mathrm{~g}$ of $\mathrm{Cecl}_{3} \cdot 7 \mathrm{H}_{2} \mathrm{O}$ is added gradually and stirred continuously. The reaction mixture is further refluxed in a round bottomed flask at $90^{\circ} \mathrm{C}$ for the time period of 4 hours. After the completion of reaction, the crude product is poured onto the beaker containing crushed ice and stirred for 10-15 min., to get the solid product. The crude sample is washed well with cold water and recrystallized using absolute ethanol. The reaction scheme of novel THPC is shown in the Scheme- 1 .

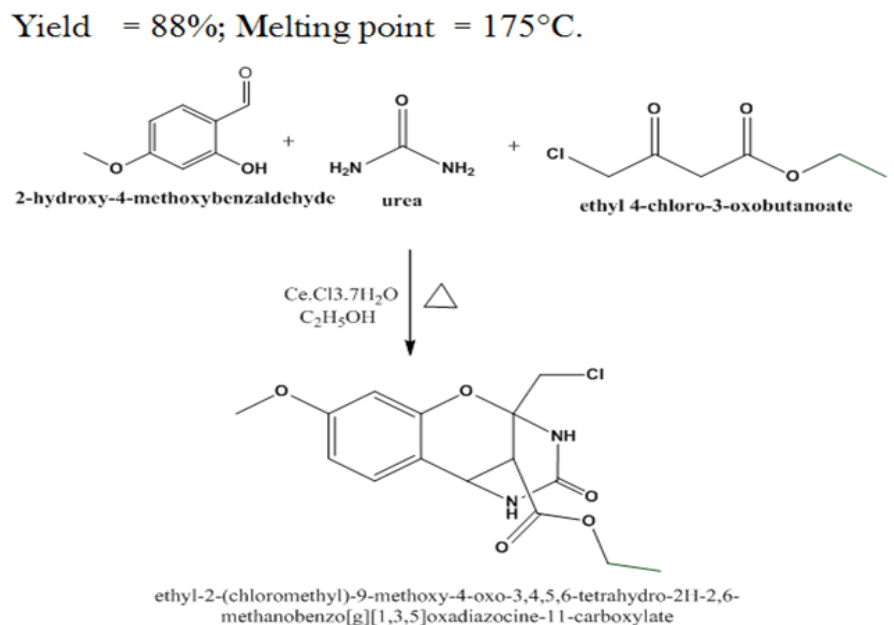

Scheme 1.The synthesis reaction scheme of THPC

\section{Spectral identification}

${ }^{1} \mathrm{H}-\mathrm{NMR}\left(300 \mathrm{MHz}, \mathrm{DMSOD}_{6}\right): \delta=7.78$

(s, $1 \mathrm{H}, \mathrm{NH}), 7.40-7.42(\mathrm{~s}, 1 \mathrm{H}, \mathrm{NH}), 6.43-7.13$

$(\mathrm{m}, 3 \mathrm{H}, \operatorname{ArC}-\mathrm{H}), 4.45(\mathrm{~s}, 1 \mathrm{H}, \mathrm{CH}), 4.32-4.36$

$(\mathrm{d}, 1 \mathrm{H}, \mathrm{CH})$ 4.14-4.25 (q, $\left.{ }_{2} \mathrm{H}, \mathrm{CH}_{2}\right), 3.93-3.97\left(\mathrm{~d},{ }_{2} \mathrm{H}\right.$,
$\left.\mathrm{CH}_{2} \mathrm{Cl}\right), 3.71\left(\mathrm{~s}, 3 \mathrm{H}, \mathrm{OCH}_{3}\right), 1.21-1.26\left(\mathrm{t}, 3 \mathrm{H}, \mathrm{CH}_{3}\right)$. ${ }^{13} \mathrm{C}$ NMR $(75 \mathrm{MHz}$, DMSO-D 6 ) $\delta=167.8,160.3$, 154.1, 151.1, 129.4, 117.2, 108.0, 101.3, 84.1, 60.9, 55.2, 47.0, 46.2, 41.1, 13.9. FT-IR ( $\mathrm{KBr}$ pellet) $\mathrm{cm}^{-1}$ $=3205,3072,1739,1687,1619,1501,1204,1156$, 
1029, 784. FT-Raman $(\mathrm{KBr}) \mathrm{cm}^{-1}=3203,3084$, 3002, 1703, 1672, 1453, 1236, 1015, 773.

\section{Characterization techniques}

The infrared spectrum of THPC in the range of $4000-400 \mathrm{~cm}^{-1}$ was recorded with the device of Shimadzu FT-IR spectrophotometer (resolution of $4 \mathrm{~cm}^{-1}$ ). The FT-Raman spectrum in the spectral range of $3500-50 \mathrm{~cm}^{-1}$ was recorded using Bruker RFS27 spectrometer operating at $100 \mathrm{~mW}$ laser. The NMR $\left({ }^{1} \mathrm{H} \&{ }^{13} \mathrm{C}\right)$ spectra of THPC were recorded using Bruker $300 \mathrm{MHz}$ spectrometer.

\section{Quantum calculation details}

The ground state geometry of THPC has been simulated by using B3LYP hybrid functional level with $6-311++G(d, p)$ basis set. The entire quantum chemical calculations were performed with Gaussian 03 software $^{12}$. The initial structural parameters of THPC were minimized in potential surface scan. The harmonic wavenumbers were calculated for the energy minimum structure and the wavenumbers were properly scaled by 0.96 . The vibration bands were precisely assigned based on the percentage contributions of potential energy distributions ${ }^{13}$. The calculated Raman activities were transformed into intensity using Raint Program ${ }^{14,15}$.

\section{RESULTS AND DISCUSSION}

\section{Structural Analysis}

The preliminary search for the stable conformer of THPC is identified from the scanned points of potential energy surface. The dihedral angles $\mathrm{D} 1\left(\mathrm{C}_{5}-\mathrm{C}_{4}-\mathrm{O}_{34}-\mathrm{C}_{35}\right), \mathrm{D} 2\left(\mathrm{C}_{3}-\mathrm{C}_{4}-\mathrm{O}_{34}-\mathrm{C}_{35}\right)$, D3 $\left(\mathrm{C}_{14}-\mathrm{C}_{11}-\mathrm{C}_{20}-\mathrm{O}_{28}\right)$ and $\mathrm{D} 4\left(\mathrm{C}_{11}-\mathrm{C}_{20}-\mathrm{O}_{28}-\mathrm{C}_{21}\right)$ are the internal redundant coordinates used for the free rotation of the molecule. While processing the PES scan, the structural parameters are relaxed such as D1, D2, D3 and D4 torsional angles are raised from $0^{\circ}$ to $360^{\circ}$ rotations with $10^{\circ}$ intervals at each step. The potential energy surface scan curves of four dihedrals of THPC are presented in Fig 1. The various conformers of THPC and its energies are presented in Table 1. The dihedral angles D1 and D2 are scanned using the torsional barrier of the methoxy side chain around the bond $\mathrm{C}_{4}-\mathrm{O}_{34}$. Dihedral angle D3 and D4 are scanned using the torsional barrier of the exocyclic ester ring around the bonds, $\mathrm{C}_{11}-\mathrm{C}_{20}$ and $\mathrm{C}_{20}-\mathrm{O}_{28}$, by varying the torsional perturbation.
From Fig. 1, it is clearly shown that numerous similar structures have been identified with different geometries and minimum energy conformers of the four scans are handier to one another. From the PES result, four minimum energy conformers have been obtained at $180^{\circ}$ with relative energy of -1527.70801 Hartree for $\mathrm{C}_{5}-\mathrm{C}_{4}-\mathrm{O}_{34}-\mathrm{C}_{35}$ and $\mathrm{C}_{3}-\mathrm{C}_{4}-\mathrm{O}_{34}-\mathrm{C}_{35}$, $170^{\circ}$ with relative energy of -1527.70953 Hartree for $\mathrm{C}_{14}-\mathrm{C}_{11}-\mathrm{C}_{20}-\mathrm{O}_{28}, 180^{\circ}$ with relative energy of -1527.70951 Hartree for $C_{11}-C_{20}-O_{28}-C_{21}$. Finally, the minimum energy conformer is identified in the internal rotation of $D 3\left(C_{14}-C_{11}-C_{20}-O_{28}\right)$ with relative energy of -1527.70953 Hartree, yielded more stable conformer and is used for further investigation. The optimized structure of THPC with intramolecular hydrogen bonding is shown in Figure 2 .

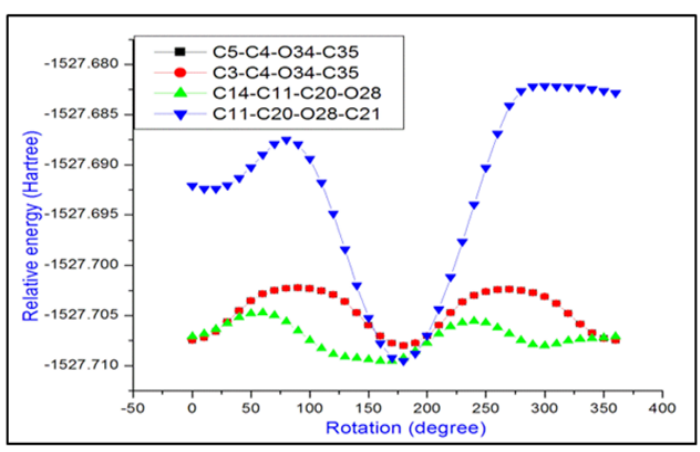

Fig. 1. The various scanned points of THPC

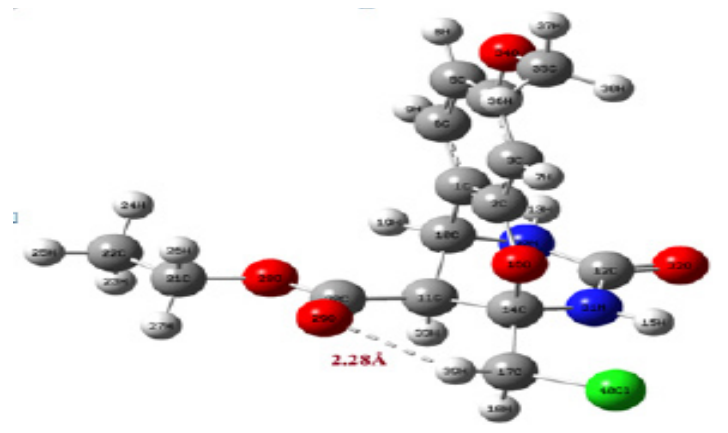

Fig. 2. The optimized structure and intramolecular hydrogen bonding of THPC

Identification of intramolecular hydrogen bond

The existence of hydrogen bondings in a molecule have shown pronounced effects on molecular structural properties ${ }^{16}$. In this investigation, the intramolecular hydrogen bonding is found between the carbonyl oxygen of the ester group with the chlorine attached methylene group. The shorter distance of $2.28 \AA$, is calculated for the $\mathrm{C}=\mathrm{O} \cdots \mathrm{H}-\mathrm{C}$ 
intramolecular hydrogen bond exist in THPC. The $2.28 \AA$ distance is noticeably lesser than the 2.72 $\AA$ Van der Waals radii of the hydrogen and oxygen atoms ${ }^{17}$. From the structural conformation, it is found that the bond length of $\mathrm{C}_{17}-\mathrm{H}_{39}(1.083 \AA)$ is shorten then the $\mathrm{C}_{17}-\mathrm{H}_{18}(1.9 \AA)$ bond length, which is owing to moderate hydrogen bonding $\mathrm{C}-\mathrm{H} \cdots \mathrm{O}$ and re- hybridization occurs it. For the strengthening of $\mathrm{C}-\mathrm{H}$ in hydrogen bonding, the stretching wavenumber get increases and bending wavenumber decreases. Normally, the $\mathrm{C}-\mathrm{H}$ aliphatic stretching vibrations are absorbed below $3000 \mathrm{~cm}^{-1}$. In this case of hydrogen bonding, the $\mathrm{C}_{17}-\mathrm{H}_{39}$ and $\mathrm{C}_{17}-\mathrm{H}_{18}$ asymmetric stretching vibration is blue shifted and computed at $3116 \mathrm{~cm}^{-1}$.

Table 1: The energies of various possible conformers of THPC

\begin{tabular}{|c|c|c|c|c|}
\hline Rotation $\left(^{\circ}\right)$ & C5-C4-O34-C35 & С3-C4-О34-С35 & C14-C11-C20-O28 & C11-C20-O28-C21 \\
\hline 0 & -1527.707453 & -1527.707453 & -1527.707098 & -1527.69209 \\
\hline 10 & -1527.707214 & -1527.707214 & -1527.70681 & -1527.692397 \\
\hline 20 & -1527.706587 & -1527.706587 & -1527.706373 & -1527.692394 \\
\hline 30 & -1527.705632 & -1527.705632 & -1527.705796 & -1527.692051 \\
\hline 40 & -1527.704534 & -1527.704534 & -1527.705204 & -1527.691317 \\
\hline 50 & -1527.703525 & -1527.703525 & -1527.7048 & -1527.690241 \\
\hline 60 & -1527.702847 & -1527.702847 & -1527.704733 & -1527.688994 \\
\hline 70 & -1527.702489 & -1527.702489 & -1527.704996 & -1527.687934 \\
\hline 80 & -1527.702283 & -1527.702283 & -1527.705612 & -1527.687498 \\
\hline 90 & -1527.702212 & -1527.702212 & -1527.706504 & -1527.687955 \\
\hline 100 & -1527.702298 & -1527.702298 & -1527.707459 & -1527.689394 \\
\hline 110 & -1527.702522 & -1527.702522 & -1527.708275 & -1527.69179 \\
\hline 120 & -1527.702917 & -1527.702917 & -1527.708835 & -1527.694891 \\
\hline 130 & -1527.703613 & -1527.703613 & -1527.709107 & -1527.698384 \\
\hline 140 & -1527.704707 & -1527.704707 & -1527.70923 & -1527.701987 \\
\hline 150 & -1527.705959 & -1527.705959 & -1527.709396 & -1527.705217 \\
\hline 160 & -1527.707037 & -1527.707037 & -1527.709524 & -1527.707767 \\
\hline 170 & -1527.707756 & -1527.707756 & -1527.709531 (min.) & -1527.709193 \\
\hline 180 & -1527.708005 & -1527.708005 & -1527.709247 & -1527.70951 \\
\hline 190 & -1527.707745 & -1527.707745 & -1527.708562 & -1527.708799 \\
\hline 200 & -1527.707028 & -1527.707028 & -1527.707728 & -1527.707014 \\
\hline 210 & -1527.70596 & -1527.70596 & -1527.706825 & -1527.704378 \\
\hline 220 & -1527.704725 & -1527.704725 & -1527.706103 & -1527.701145 \\
\hline 230 & -1527.703653 & -1527.703653 & -1527.705716 & -1527.697637 \\
\hline 240 & -1527.702989 & -1527.702989 & -1527.705563 & -1527.693976 \\
\hline 250 & -1527.70262 & -1527.70262 & -1527.705708 & -1527.690292 \\
\hline 260 & -1527.702424 & -1527.702424 & -1527.706225 & -1527.686897 \\
\hline 270 & -1527.702382 & -1527.702382 & -1527.70681 & -1527.684095 \\
\hline 280 & -1527.702493 & -1527.702493 & -1527.707461 & -1527.682631 \\
\hline 290 & -1527.702735 & -1527.702735 & -1527.707904 & -1527.682208 \\
\hline 300 & -1527.703117 & -1527.703117 & -1527.707999 & -1527.682131 \\
\hline 310 & -1527.7038 & -1527.7038 & -1527.707809 & -1527.682171 \\
\hline 320 & -1527.704796 & -1527.704796 & -1527.707513 & -1527.682233 \\
\hline 330 & -1527.705851 & -1527.705851 & -1527.707351 & -1527.682273 \\
\hline 340 & -1527.706725 & -1527.706725 & -1527.707273 & -1527.682465 \\
\hline 350 & -1527.707283 & -1527.707283 & -1527.707192 & -1527.682653 \\
\hline 360 & -1527.707453 & -1527.707453 & -1527.707097 & -1527.682824 \\
\hline
\end{tabular}


In addition the strength of the intramolecular hydrogen bond is identified by donor-acceptor interactions. From NBO results, the charge transfer interaction from (LP) $\mathrm{O}_{29} \rightarrow \sigma^{*}\left(\mathrm{C}_{17}-\mathrm{H}_{39}\right)$ leads the moderate stabilization of $1.56 \mathrm{kcal} / \mathrm{mol}$. The weak hydrogen bonding energy of charge transfer between the elements lies in the range between $0-4 \mathrm{kcal} / \mathrm{mol}$, but can sometimes be rise up to $40 \mathrm{kcal} / \mathrm{mol}$. The ED value of the $\mathrm{C}_{17}-\mathrm{H}_{39}$ is found as $0.0184 \mathrm{e}$, which is comparably less than other $\mathrm{C}-\mathrm{H}$ bonds of the THPC molecular system. These results strongly assure the formation of hydrogen bonding in THPC at intramolecular level with the distance of $2.28 \AA$.

\section{Vibrational Spectral Assignments}

The THPC has 40 atoms and fits to $\mathrm{C} 1$ point group symmetry, which gives rise 114 normal modes of vibration. The scaled wavenumbers have been studied from Potential Energy Distributions
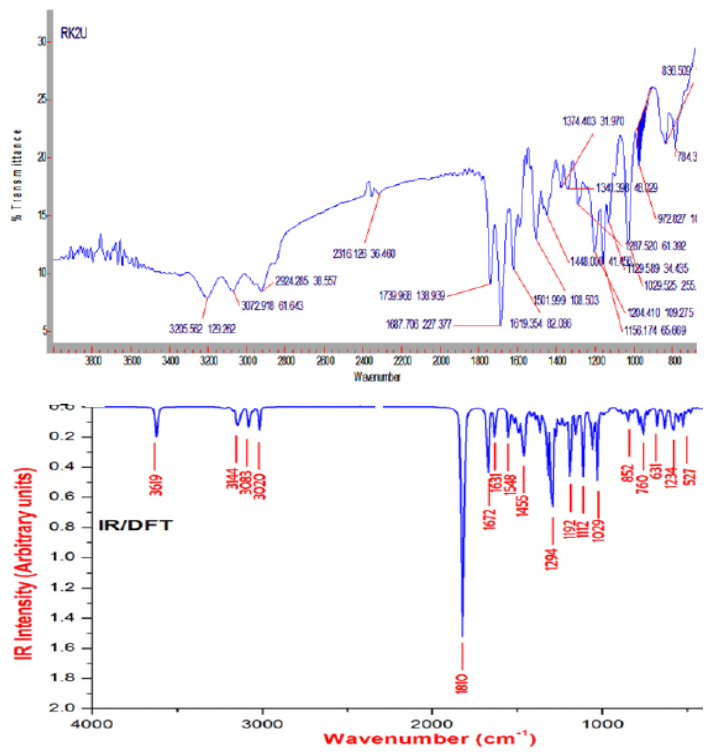

(PED). The Fourier Transformed experimental and theoretical (IR \& RAMAN) vibrational spectra of THPC are shown in Fig. 3. The NMR $\left({ }^{1} \mathrm{H} \&{ }^{13} \mathrm{C}\right)$ spectra of THPC are shown in Fig. 4. The experimental and calculated wavenumbers with detailed PED assignments are presented in Table S1. To overcome the discrepancies between experimental and theoretical wavenumber, the proper scale factor has used to scale down the theoretical wavenumbers suggested by Computational Chemistry Comparison in Benchmark Database ${ }^{18}$.

\section{N-H and C-N Vibrations}

Aromatic $\mathrm{N}-\mathrm{H}$ stretching wavenumbers normally occur in the $3500-3300 \mathrm{~cm}^{-1}$ spectral region ${ }^{19}$. The strong vibrational band observed at $3205 \mathrm{~cm}^{-1}$ in FT-IR and a weak band at $3203 \mathrm{~cm}^{-1}$ in FT-Raman is attributed to $\mathrm{N}-\mathrm{H}$ stretching vibration. The harmonic wavenumber at 3488 and $3482 \mathrm{~cm}^{-1}$
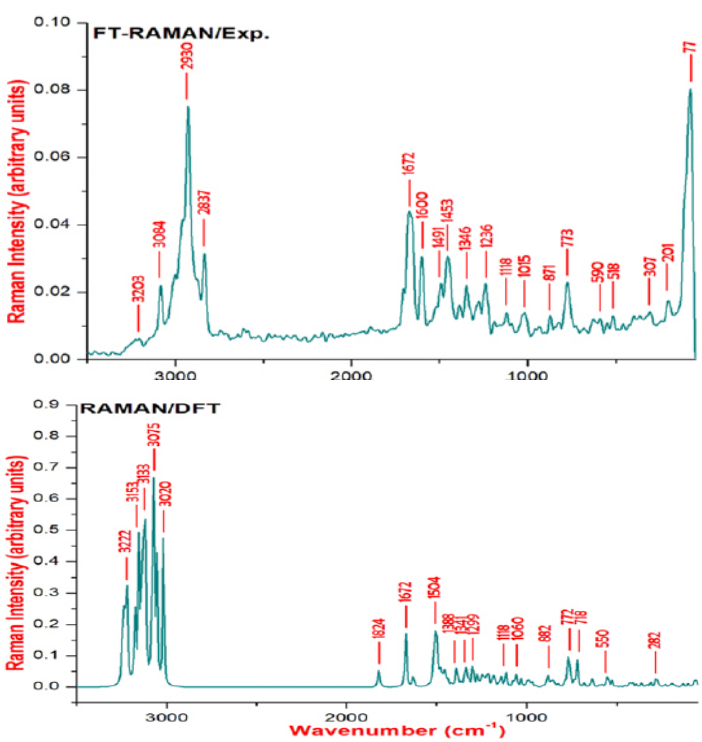

Fig. 3. The experimental and theoretical FT-IR and FT-Raman spectra of THPC

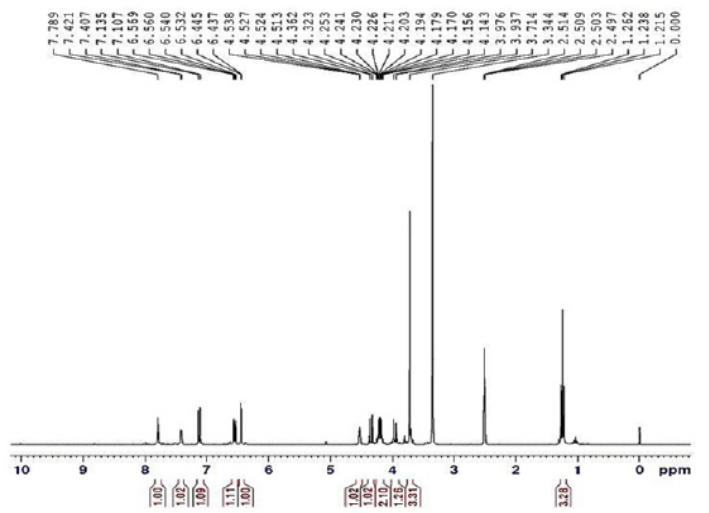

Fig. 4. The ${ }^{1} \mathrm{H}$ and ${ }^{13} \mathrm{C}-\mathrm{NMR}$ spectra of THPC 
are assigned for $\mathrm{N}_{30} \mathrm{H}_{13}$ and $\mathrm{N}_{31} \mathrm{H}_{15}$ bonds. Due to the hydrogen bonding interaction the experimental wavenumber is observed in lower wavenumber region in the solid state and is not observed in the isolated molecule. The $97 \%$ of the PED contribution of $\mathrm{N}-\mathrm{H}$ vibration shows, these are pure mode of vibration. The chemical shifts $\delta \mathrm{H}$ at 7.421 and 7.789 ppm in downfield region of the proton NMR have assigned for the deshielded $\mathrm{N}-\mathrm{H}$ protons of the pyrimidine ring. Silverstein assigned the stretching C-N vibrations in the vibrational region of 1382-1266 $\mathrm{cm}^{-1} 20$. The results are very intricate to identify the $\mathrm{C}-\mathrm{N}$ vibration, the band observed at $1374 \mathrm{~cm}^{-1}$ in FT-IR and theoretical wavenumber at $1364 \mathrm{~cm}^{-1}$ are assigned to $\beta \mathrm{CNH}$ vibration. The $v \mathrm{C}-\mathrm{N}$ vibrations are computed at 1409 and $1400 \mathrm{~cm}^{-1}$ from B3LYP method.

\section{$\mathrm{C}=\mathrm{O}$ and $\mathrm{C}-\mathrm{O}$ vibrations}

Normally the $\mathrm{C}=\mathrm{O}$ bonds have an intense peaks in the region $1800-1600 \mathrm{~cm}^{-1}{ }^{21}$. The $\mathrm{vC}=\mathrm{O}$ vibrations are mainly based on the bond strength, which depends on the conjugative, steric effect and lone pair electron present in it ${ }^{22}$. The peaks obtain which are at $1739 \mathrm{~cm}^{-1}$ in IR and $1703 \mathrm{~cm}^{-1}$ in Raman have been recognized vibrations of carbonyl group of the dihydropyrimidine with $100 \%$ IR intensity. Similarly the bands appears at $1687 \mathrm{~cm}^{-1}$ in IR and at $1672 \mathrm{~cm}^{-1}$ in Raman corresponds for the ester group carbonyl vibration. Their corresponding harmonic wavenumbers are 1755 and $1742 \mathrm{~cm}^{-1}$. The signals observe at 167.84 and $160.30 \mathrm{ppm}$ in ${ }^{13} \mathrm{C}-\mathrm{NMR}$ confirms the carbonyl carbons of THPC. The C-O vibrations are affected by the surrounding molecular interactions and are observed between1260-1000 $\mathrm{cm}^{-1} 23$.

The C-O vibrations observed at 1274 , 1236, $1015 \mathrm{~cm}^{-1}$ in FT-Raman and strong peak at $1029 \mathrm{~cm}^{-1}$ in Infrared spectrum. The calculated wavenumbers at 1269, 1244, 1032 and $1019 \mathrm{~cm}^{-1}$ represents the $\mathrm{C}-\mathrm{O}$ vibrations of methoxy and carboxylate group. In ${ }^{13} \mathrm{C}-\mathrm{NMR}$, the signal appeared at $84.10 \mathrm{ppm}$ is assigned to $\mathrm{sp}^{3} \mathrm{C}_{14}$ atom provides substantial evidence of tricyclic ring formation of THPC from the intramolecular conjugate addition of the phenolic hydroxyl to $\mathrm{C}_{2}-\mathrm{O}_{16}-\mathrm{C}_{14}$ of the dihydropyrimidine ring. The $\delta_{H}$ at 4.323-4.362 ppm attributed to the proton bonded with $\mathrm{C}_{11}$ atom which also confirms the oxygen bridged tricyclic ring exist in the title molecule.

\section{Aromatic ring vibrations}

The $v \mathrm{C}-\mathrm{H}$ vibrations in aromatic ring exhibit bands usually in the spectral range of 3100-3000 $\mathrm{cm}^{-1} 24$. In THPC, there are three $\mathrm{C}-\mathrm{H}$ bonds namely $\mathrm{C}_{3}-\mathrm{H}_{7}, \mathrm{C}_{5}-\mathrm{H}_{8}$ and $\mathrm{C}_{6}-\mathrm{H}_{9}$. The $\mathrm{vC}-\mathrm{H}$ vibrations of THPC observed at $3072 \mathrm{~cm}^{-1}$ in IR and at $3084 \mathrm{~cm}^{-1}$ in Raman as strong bands. These vibrations are theoretically computed at 3117, 3099 and $3055 \mathrm{~cm}^{-1}$ with PED contribution of $>97 \%$. The two doublets and one singlet observed at 6.56, 6.54 and $6.44 \mathrm{ppm}$ are the corresponding aromatic proton signals in ${ }^{1} \mathrm{H}$-NMR spectrum. The in-plane bending vibrations of $\mathrm{C}-\mathrm{H}$ normally observed between 1300-1000 $\mathrm{cm}^{-1} 25$. The DFT wavenumber at 1109 and $1075 \mathrm{~cm}^{-1}$ are corresponds to in-plane bending vibration of aromatic $\mathrm{C}-\mathrm{H}$.

Similarly, the out-of-plane bending $\mathrm{C}-\mathrm{H}$ vibrations occur in the region $1000-750 \mathrm{~cm}^{-1}$ as coupled vibrations ${ }^{26}$. The weak band at $821 \mathrm{~cm}^{-1}$ in Raman spectrum is the corresponding band of out-of-plane $\mathrm{C}-\mathrm{H}$ bending of THPC. The calculated wavenumber at 915,820 and $794 \mathrm{~cm}^{-1}$ are also assigned relatively with $80 \%$ of PED contribution. The $v \mathrm{C}=\mathrm{C}$ vibrations of phenyl ring usually observed in the spectral region of $1625-1430 \mathrm{~cm}^{-1} 27$. In this investigation, sharp bands at $1619,1501 \mathrm{~cm}^{-1}$ in IR and $1600,1491 \mathrm{~cm}^{-1}$ in Raman bands represents $v C=C$ vibrations of phenyl ring. These vibration modes are calculated at 1609,1569 and $1490 \mathrm{~cm}^{-1}$ from the DFT method. In ${ }^{13} \mathrm{C}-\mathrm{NMR}$ spectrum the signals observed at $101.37-129.40 \mathrm{ppm}$ are the responsible carbon signals of phenyl ring.

\section{C-H Vibrations}

The $v \mathrm{C}-\mathrm{H}$ (as) vibrations of methyl group is appeared in the spectral region $3010-2940 \mathrm{~cm}^{-1}$ and $\mathrm{vC}-\mathrm{H}(\mathrm{s})$ stretching vibrations in the spectral range of $2970-2840 \mathrm{~cm}^{-1} 28$. In THPC, there are two methyl groups one at methoxy and another one at ethyl group of the acetate chain. The wavenumber observed at $2930 \mathrm{~cm}^{-1}$ in Raman spectrum and at $2924 \mathrm{~cm}^{-1}$ in IR spectrum are allocated to symmetric stretching $\mathrm{C}-\mathrm{H}$ bands of the methyl groups present in methoxy and ethyl side chains. The asymmetric vibrations of methyl moities are identified at 3014 and $2966 \mathrm{~cm}^{-1}$. The vibrations of symmetric $\mathrm{vC}-\mathrm{H}$ stretching are identified at 2942 and $2905 \mathrm{~cm}^{-1}$ with $90 \%$ of PED. In ${ }^{13} \mathrm{C}-\mathrm{NMR}$ spectrum, the carbon signals appeared at 55.21 and 13.90 ppm are corresponding to $C_{13}$ and 
$\mathrm{C}_{22}$ methyl groups. Whereas, the singlet and triplet observed at 3.714 and 1.215-1.262 ppm confirms the protons of methoxy and methyl group in ester chain of the THPC.

The stretching modes of methylene groups are expected to occur at 2935 and 2865 $\mathrm{cm}^{-1}$, respectively ${ }^{29}$. The acetate moiety methylene vibrations are calculated at 3000 and $2959 \mathrm{~cm}^{-1}$ The quartet signal observed at 4.143-4.253 $\mathrm{ppm}$ is corresponds to the methylene protons. The asymmetric stretching vibrations of chlorine attached $\mathrm{CH}_{2}$ group absorb nearly $3100 \mathrm{~cm}^{-1}$, and symmetric $\mathrm{CH}_{2}$ stretching nearly $2986 \mathrm{~cm}^{-1}{ }^{30}$. The asymmetric and symmetric wavenumbers of chlorine attached methylene group is calculated at 3116 and $3012 \mathrm{~cm}^{-1}$, respectively. The blue-shifting in the wavenumber indicating the improper intramolecular hydrogen bonding occur in the THPC. The aliphatic $\mathrm{C}_{10}-\mathrm{H}_{9}$ and $\mathrm{C}_{11}-\mathrm{H}_{33}$ vibrations are calculated at 3004 and $2958 \mathrm{~cm}^{-1}$. The sharp band observed at $3002 \mathrm{~cm}^{-1}$ is attributed for the tetrahydropyrimidine aliphatic $\mathrm{C}-\mathrm{H}$ vibration of the ring.

\section{Vibrations of $\mathbf{C}-\mathrm{Cl}$}

The $v \mathrm{C}-\mathrm{X}(\mathrm{x}=\mathrm{Cl})$ vibration bands are usually observed in the region of 760-505 $\mathrm{cm}^{-1}$; here the combinations of band are possible due to heavy atom and lowering the molecular symmetry ${ }^{31}$. The $v \mathrm{C}-\mathrm{Cl}$ vibration is appeared at $784 \mathrm{~cm}^{-1}$ in FT-IR spectrum and $773 \mathrm{~cm}^{-1}$ in FT-Raman with $83 \%$ of PED contribution. The theoretical band at $783 \mathrm{~cm}^{-1}$ well matched with the experimental finding. The chlorine substituted methylene group shown doublet signal at 3.937-3.976 ppm, instead of singlet the splitting is may be due to the improper hydrogen bonding existing in the THPC molecule. The chlorine bonded carbon signal is observed at $47.09 \mathrm{ppm}$ in carbon NMR spectrum.

\section{Donor-acceptor interaction analysis}

The bonding and anti-bonding interactions can be significantly described by natural bond orbitals, which is expressed in terms of the second order perturbation energies $\left(E^{(2)}\right)^{32-35}$. These interaction energies represent the estimation of NBO Fock matrix. The $E^{(2)}$ values of donor-acceptor bonds are given in Table 2 and it reveals, the various interactions between the donor/acceptor orbitals of THPC.
The lone pair of $\mathrm{O}_{28}$ and the $\mathrm{C}_{20}-\mathrm{O}^{29}$ of the ester group has shown stabilization energy of about $212.97 \mathrm{KJ} / \mathrm{mol}$. This large stabilization energy indicates delocalization of electron density in the carboxylate group. Thus it confirms the strong bonding between the oxygen and carbonyl group of the exocyclic ester side chain. In the title molecule, the strong hyperconjugative interaction has observed between lone pair electron of oxygen atom with $\sigma$ and $\pi$ anti-bonding electrons of $\mathrm{C}-\mathrm{O}, \mathrm{C}-\mathrm{N}$ and $\mathrm{C}-\mathrm{C}$. Enormous stabilization energies were found for lone pair electrons of oxygen atoms show $\operatorname{LP}\left(\mathrm{O}_{29}\right) \rightarrow \sigma^{*}\left(\mathrm{C}_{20}-\mathrm{O}_{28}\right), \operatorname{LP}\left(\mathrm{O}_{34}\right) \rightarrow \pi^{*}(\mathrm{C} 3-\mathrm{C} 4)$, $\operatorname{LP}\left(\mathrm{O}_{16}\right) \rightarrow \pi^{*}\left(\mathrm{C}_{1}-\mathrm{C}_{2}\right), \operatorname{LP}\left(\mathrm{O}_{32}\right) \rightarrow \pi^{\star}\left(\mathrm{C}_{12}-\mathrm{N}_{30}\right)$, $\left(\mathrm{C}_{12}-\mathrm{N}_{31}\right)$ interaction gives the stabilization energies of $138.45,135.23,122.59,106.61$ and $112.05 \mathrm{KJ} / \mathrm{mol}$.

The lone pair electrons of nitrogen atom have shown moderate stabilization energies of 59.16 and $70.25 \mathrm{KJ} / \mathrm{mol}$ are derived from the interactions of $\mathrm{LP}\left(\mathrm{N}_{30}\right) \rightarrow \mathrm{C}_{12}-\mathrm{O}_{32}$, $\mathrm{LP}\left(\mathrm{N}_{31}\right) \rightarrow \mathrm{C}_{12}-\mathrm{O}_{32}$. The stability confirmation between pyran and tetrahydropyrimidine ring has established by the lone pair electron of $\mathrm{N}_{31} \rightarrow \sigma^{*}\left(\mathrm{C}_{14}-\mathrm{O}_{16}\right)$ leads to the stabilization of 78.32 $\mathrm{KJ} / \mathrm{mol}$. From the NBO analysis, the aromatic (c-c) donor $\pi(\sim 1.67-1.72 e)$ and acceptor $\pi^{*}(\sim 0.32-0.41)$ leads to the molecular stabilization of 60.63-101.04 $\mathrm{KJ} / \mathrm{mol}$. The electron density movement from donor $\rightarrow$ acceptor $(\mathrm{C}-\mathrm{C})$ interaction increases $\mathrm{ED} / \mathrm{e}$ in anti-bonding orbital that weakens the respective bonds. This makes the high polarization and causes intra molecular charge transfer in the THPC compound.

\section{Nonlinear optical analysis}

The first hyperpolarizabilities $\left(\beta_{0}, \alpha_{0}\right.$ and $\left.\Delta \alpha\right)$ of THPC is calculated using DFT level of theory. The first hyperpolarizability tensors can be described by Kleinman symmetry ${ }^{36}$. The calculated dipole moment $(\alpha)$, polarizability $(\mu)$ and first hyperpolarizability $(\beta 0)$ of THPC is,

- $\quad$ Calculated dipole moment $=2.0990$ Debye

- $\quad$ Calculated polarizability $=3.7840 \times 10^{-30} \mathrm{esu}$

- $\quad$ First hyperpolarizability $=2.7495 \times 10^{-30} \mathrm{esu}$

The first hyperpolarizability $\beta_{\text {tot }}$ of THPC calculated as $2.75 \times 10^{-30}$ esu. The dominated longitudinal compounds $\beta_{\mathrm{xxx}}, \beta_{\mathrm{YY} Y}, \beta_{\mathrm{XXz}}$ and $\beta_{\mathrm{YZZ}}$ shows large value of specific components indicates the significant charge delocalization in this direction. 
The calculated polarizability ' $\alpha$ ' has non-zero value and dominated by the diagonal components. The first hyperpolarizability components of THPC are presented in Table 3. The first hyperpolarizability of
THPC has seven times higher than reference Urea. Hence THPC has good nonlinear response and it is a good candidate in optical studies.

Table 2: The donor-acceptor interactions of THPC

\begin{tabular}{|c|c|c|c|c|c|c|c|c|}
\hline Type & Donor & $\mathrm{ED} / \mathrm{e}$ & Acceptor & $\mathrm{ED} / \mathrm{e}$ & $\mathrm{E}^{(2)} \mathrm{kJ} / \mathrm{mol}$ & ${ }^{\mathrm{a}} \mathrm{E}^{(2)} \mathrm{Kcal} / \mathrm{mol}$ & ${ }^{b} E(j)-E(i)$ a.u & ${ }^{c} F(i, j) a . u$ \\
\hline$\pi-\pi^{\star}$ & $\mathrm{C}_{1}-\mathrm{C}_{2}$ & 1.6751 & $\mathrm{C}_{1}-\mathrm{C}_{2}$ & 0.4176 & 7.15 & 1.71 & 0.29 & 0.02 \\
\hline$\pi-\pi^{\star}$ & $\mathrm{C}_{1}-\mathrm{C}_{2}$ & & $\mathrm{C}_{3}-\mathrm{C}_{4}$ & 0.3877 & 60.63 & 14.49 & 0.29 & 0.058 \\
\hline$\pi-\pi^{*}$ & $\mathrm{C}_{1}-\mathrm{C}_{2}$ & & $\mathrm{C}_{5}-\mathrm{C}_{6}$ & 0.3239 & 97.7 & 23.35 & 0.29 & 0.074 \\
\hline$\pi-\sigma^{*}$ & $\mathrm{C}_{1}-\mathrm{C}_{2}$ & & $\mathrm{C}_{10}-\mathrm{H}_{19}$ & 0.0187 & 4.31 & 1.03 & 0.72 & 0.026 \\
\hline$\pi-\sigma^{*}$ & $\mathrm{C}_{1}-\mathrm{C}_{2}$ & & $\mathrm{C}_{10}-\mathrm{N}_{30}$ & 0.0412 & 24.35 & 5.82 & 0.6 & 0.057 \\
\hline \multirow[t]{3}{*}{$\pi-\pi^{*}$} & $\mathrm{C}_{3}-\mathrm{C}_{4}$ & 1.6868 & $C_{1}-C_{2}$ & 0.4176 & 101.04 & 24.15 & 0.29 & 0.076 \\
\hline & & & $\mathrm{C}_{3}-\mathrm{C}_{4}$ & 0.3877 & 4.52 & 1.08 & 0.29 & 0.016 \\
\hline & & & $\mathrm{C}_{5}-\mathrm{C}_{6}$ & 0.3239 & 62.47 & 14.93 & 0.29 & 0.059 \\
\hline \multirow[t]{2}{*}{$\pi-\pi^{*}$} & $\mathrm{C}_{5}-\mathrm{C}_{6}$ & 1.7282 & $\mathrm{C}_{1}-\mathrm{C}_{2}$ & 0.4176 & 64.48 & 15.41 & 0.28 & 0.061 \\
\hline & & & $\mathrm{C}_{3}-\mathrm{C}_{4}$ & 0.3877 & 92.88 & 22.2 & 0.28 & 0.072 \\
\hline \multirow[t]{3}{*}{$\mathrm{n}-\pi^{*}$} & $\mathrm{LP}(2) \mathrm{O}_{16}$ & 1.8408 & $C_{1}-C_{2}$ & 0.4176 & 122.59 & 29.3 & 0.34 & 0.096 \\
\hline & & & $C_{11}-C_{14}$ & 0.0432 & 13.43 & 3.21 & 0.63 & 0.041 \\
\hline & & & $\mathrm{C}_{14}-\mathrm{N}_{31}$ & 0.0536 & 42.3 & 10.11 & 0.67 & 0.076 \\
\hline \multirow[t]{3}{*}{$n-\pi^{*}$} & $\mathrm{LP}(2) \mathrm{O}_{28}$ & 1.7846 & $\mathrm{C}_{20}-\mathrm{O}_{29}$ & 0.2229 & 212.97 & 50.9 & 0.33 & 0.116 \\
\hline & & & $\mathrm{C}_{21}-\mathrm{H}_{26}$ & 0.0188 & 16.78 & 4.01 & 0.78 & 0.053 \\
\hline & & & $\mathrm{C}_{21}-\mathrm{H}_{27}$ & 0.0191 & 16.57 & 3.96 & 0.78 & 0.052 \\
\hline \multirow[t]{3}{*}{$n-\sigma^{*}$} & $\mathrm{LP}(2) \mathrm{O}_{29}$ & 1.8456 & $\mathrm{C}_{11}-\mathrm{C}_{20}$ & 0.0667 & 82.51 & 19.72 & 0.63 & 0.102 \\
\hline & & & $\mathrm{C}_{17}-\mathrm{H}_{39}$ & 0.0184 & 6.53 & 1.56 & 0.75 & 0.032 \\
\hline & & & $\mathrm{C}_{20}-\mathrm{O}_{28}$ & 0.0970 & 138.45 & 33.09 & 0.64 & 0.132 \\
\hline \multirow[t]{4}{*}{$\mathrm{n}-\pi^{*}$} & $\mathrm{LP}(1) \mathrm{N}_{30}$ & 1.7846 & $\mathrm{C}_{1}-\mathrm{C}_{2}$ & 0.4176 & 5.15 & 1.23 & 0.31 & 0.018 \\
\hline & & & $\mathrm{C}_{1}-\mathrm{C}_{10}$ & 0.0406 & 34.56 & 8.26 & 0.68 & 0.07 \\
\hline & & & $\mathrm{C}_{12}-\mathrm{O}_{32}$ & 0.1544 & 45.1 & 10.78 & 0.65 & 0.076 \\
\hline & & & $\mathrm{C}_{12}-\mathrm{O}_{32}$ & 0.215 & 59.16 & 14.14 & 0.54 & 0.078 \\
\hline \multirow[t]{4}{*}{$n-\sigma^{*}$} & $\mathrm{LP}(1) \mathrm{N}_{31}$ & 1.7526 & $\mathrm{C}_{12}-\mathrm{O}_{32}$ & 0.1544 & 40.75 & 9.74 & 0.64 & 0.072 \\
\hline & & & $\mathrm{C}_{12}-\mathrm{O}_{32}$ & 0.215 & 70.25 & 16.79 & 0.52 & 0.084 \\
\hline & & & $\mathrm{C}_{14}-\mathrm{O}_{16}$ & 0.0881 & 78.32 & 18.72 & 0.51 & 0.091 \\
\hline & & & $\mathrm{C}_{14}-\mathrm{C}_{17}$ & 0.0402 & 9.04 & 2.16 & 0.59 & 0.034 \\
\hline \multirow[t]{2}{*}{$n-\sigma^{*}$} & $\mathrm{LP}(2) \mathrm{O}_{32}$ & 1.8452 & $\mathrm{C}_{12}-\mathrm{N}_{30}$ & 0.0774 & 106.61 & 25.48 & 0.67 & 0.119 \\
\hline & & & $\mathrm{C}_{12}-\mathrm{N}_{31}$ & 0.0821 & 112.05 & 26.78 & 0.67 & 0.122 \\
\hline \multirow[t]{3}{*}{$\mathrm{n}-\pi^{*}$} & $\mathrm{LP}(2) \mathrm{O}_{34}$ & 1.8353 & C3-C4 & 0.3877 & 135.23 & 32.32 & 0.34 & 0.099 \\
\hline & & & $\mathrm{C}_{35}-\mathrm{H}_{36}$ & 0.0192 & 22.55 & 5.39 & 0.74 & 0.059 \\
\hline & & & $\mathrm{C}_{35}-\mathrm{H}_{38}$ & 0.0191 & 22.34 & 5.34 & 0.74 & 0.058 \\
\hline \multirow[t]{2}{*}{$n-\sigma^{*}$} & $\mathrm{LP}(2) \mathrm{CI}_{40}$ & 1.9826 & $\mathrm{C}_{17}-\mathrm{H}_{18}$ & 0.0142 & 11.84 & 2.83 & 0.76 & 0.041 \\
\hline & & & $\mathrm{C}_{17}-\mathrm{H}_{39}$ & 0.0184 & 7.99 & 1.91 & 0.79 & 0.035 \\
\hline \multirow[t]{3}{*}{$n-\sigma^{*}$} & $\mathrm{LP}(3) \mathrm{Cl}_{40}$ & 1.9675 & $\mathrm{C}_{14}-\mathrm{C}_{17}$ & 0.0402 & 17.32 & 4.14 & 0.65 & 0.046 \\
\hline & & & $\mathrm{H}_{15}-\mathrm{N}_{31}$ & 0.0209 & 6.99 & 1.67 & 0.78 & 0.032 \\
\hline & & & $\mathrm{C}_{17}-\mathrm{H}_{39}$ & 0.0184 & 4.77 & 1.14 & 0.79 & 0.027 \\
\hline
\end{tabular}

a $E\left({ }^{2}\right)$ - Stabilization energy

b Donor-acceptor energy difference

c $F(i, j)$ is the fock matrix elements. 
Table 3: The first hyperpolarizability tensors of THPC

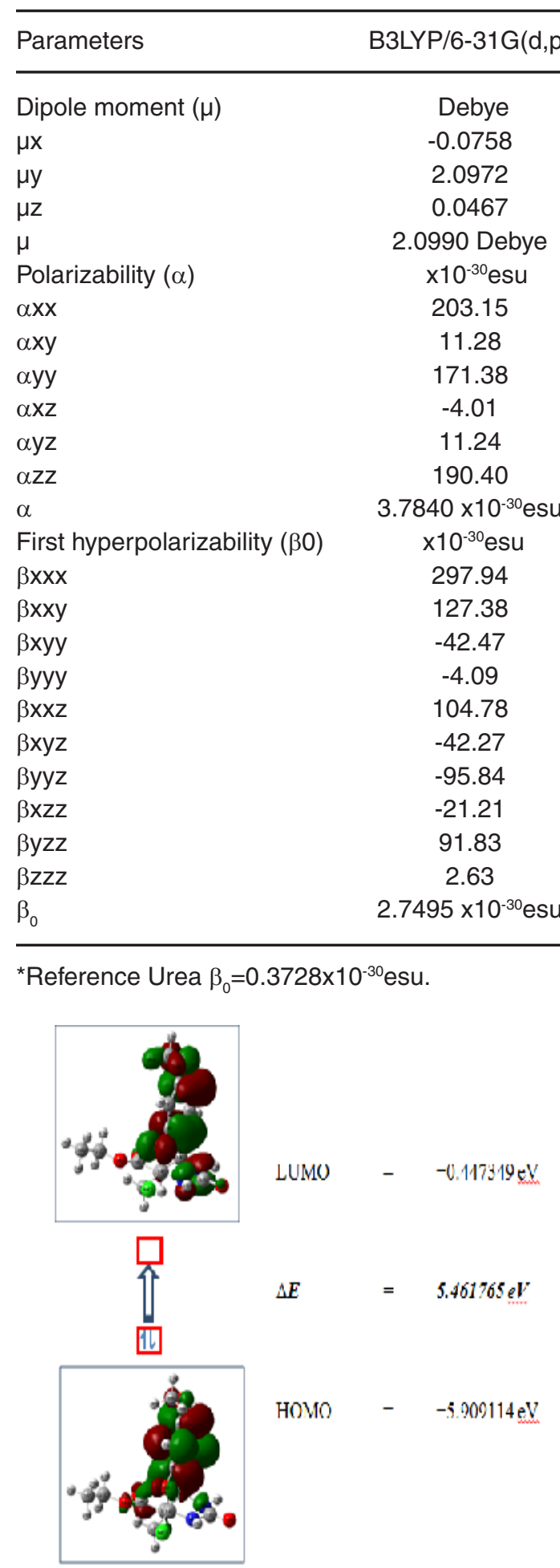

Fig. 5.The frontier molecular orbital mapped surfaces of THPC

\section{Energy gap analysis}

The energy gap of THPC explains the charge transfer interaction, which influences the biological activity of the molecule. The negative and positive phases are represented in blue and red colour, respectively. The energy from the HOMO represents the ionization potential and LOMO represents the electron affinity. The energy gap of an organic molecule is an important stability factor for chemical structures ${ }^{37}$. The three dimensional images of HOMO and LUMO orbitals are shown in Fig. 5. The frontier molecular orbitals of THPC are presented in Table 4.

Table 4: The Frontier molecular orbital energies of THPC

\begin{tabular}{lccc}
\hline Orbitals & $\mathrm{a} . \mathrm{u}$ & $\mathrm{eV}$ & $\mathrm{K} . \mathrm{E}$ \\
\hline $85 \mathrm{O}$ & -0.270504 & -7.360684 & 1.934732 \\
860 & -0.260847 & -7.097908 & 2.133515 \\
870 & -0.252113 & -6.860247 & 2.172732 \\
880 & -0.240068 & -6.53249 & 1.567225 \\
890 & -0.217159 & -5.909114 & 1.678119 \\
$90 \mathrm{~V}$ & -0.01644 & -0.447349 & 1.851026 \\
$91 \mathrm{~V}$ & 0.000347 & 0.0094422 & 1.775268 \\
$92 \mathrm{~V}$ & 0.001709 & 0.0465036 & 1.758376 \\
$93 \mathrm{~V}$ & 0.014842 & 0.4038657 & 2.170792 \\
$94 \mathrm{~V}$ & 0.053069 & 1.4440606 & 2.097917 \\
\hline
\end{tabular}

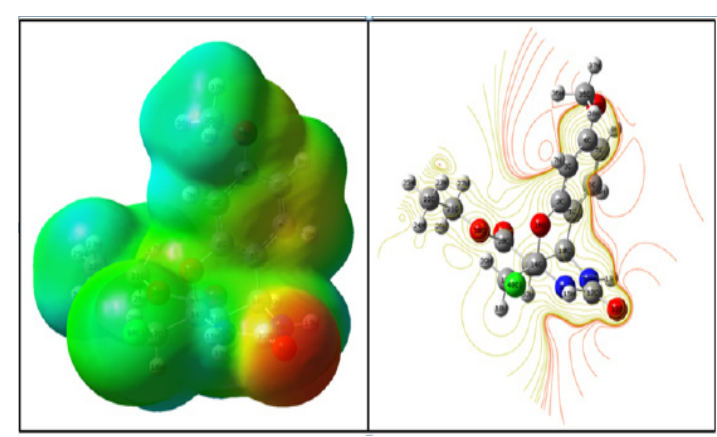

Fig. 6. The MEP and 2-D contour mapped surfaces of THPC

The energies of HOMO $=-5.9099 \mathrm{eV}$, $\mathrm{LUMO}=-0.4473 \mathrm{eV}$ and the energy gap is calculated as $5.4617 \mathrm{eV}$. The electron density at HOMO level in localized over the tetrahydropyrimidone and methoxy phenyl ring. The electron density at LUMO level is localized over the phenyl ring and carboxyl group of the exocyclic ester chain. The electron transition from $\mathrm{HOMO} \rightarrow$ LUMO implies the transfer of electron 
density from tetrahydropyrimidinone ring to aromatic ring of the title molecule.

\section{Molecular Electrostatic Potential mapped surface}

The MEP mapped surface and the contours of the THPC are shown in Fig 6. The red region in MEP refers the area that would favour lone pair interaction region predicting a site of hydrogen bonding donor. The blue region in MEP refers the area that would favour acceptor nature. In the title molecule, the red regions are observed at the oxygen atom of tetrahydropyromidinone carbonyl group and ester carbonyl group. The blue regions are observed over the two $\mathrm{N}-\mathrm{H}$ of the tetrahydropyrimidinone ring. The green regions represent the zero potential of the total molecule. The contour map of title molecule, represent the two dimension image of the electron density in the title molecule. In closer curved line represent the fractional region of the molecule, which represents the electrostatic potentially active area. These regions are responsible for the biologically active molecular interactions.

\section{CONCLUSION}

Novel organic oxygen bridged tricyclic pyrimidinones molecule is synthesized using Biginelli condensation reaction. The structural features of title molecule are studied experimentally and theoretically. The relative energy of the stable conformer is identified as -1527.70 Hartree. The conformer exists an intramolecular hydrogen bonding between ester $\mathrm{C}=\mathrm{O} \ldots \mathrm{H}-\mathrm{C}$ chlorine attached methylene with a bond distance of $2.28 \AA$. The stabilization energy of $1.56 \mathrm{Kcal} / \mathrm{mol}$ reveals the existing hydrogen bond is weak and its blue shift the $\mathrm{C}-\mathrm{H}$ wavenumber to $\sim 16 \mathrm{~cm}^{-1}$. The predicted non-linear optical property $\left(2.7495 \times 10^{-30} \mathrm{esu}\right)$ of the title compound is much higher than urea. The THPC is a good candidate for second-order NLO material. The active charge sites give information about where the THPC can have intermolecular interactions and metallic bonding.

\section{REFERENCES}

1. Mayer, T. U.; Small Molecule Inhibitor of Mitotic Spindle Bipolarity Identified in a Phenotype-Based Screen, Science., 1999, 286, 971-974.

2. Achelle, S.; Rodríguez-López, J.; Cabon, N.; and Guen, F. R. Protonable pyrimidine derivative for white light emission. RSC Adv., 2015, 5, 107396-107399.

3. Akdas-Kilig, H.; Godfroy, M.; Fillaut, J. L.; Donnio, B.; Heinrich, B.; Kedziora, P.; Malval, J.P.; Spangenberg, A.; Van Cleuvenbergen, S.; Clays, K.; Camerel, F. Mesogenic, Luminescence, and Nonlinear Optical Properties of New Bipyrimidine-Based Multifunctional Octupoles. J. Phys. Chem. C., 2015, 119, 3697-3710.

4. Kato, S.; Yamada, Y.; Hiyoshi, H.; Umezu, K.; Nakamura, Y. Series of Carbazole-Pyrimidine Conjugates: Syntheses and Electronic, Photophysical, and Electrochemical Properties. J. Org. Chem., 2015, 80, 90769090.

5. Wang, C.; Dong, H.; Hu, W.; Liu, Y.; Zhu, D. Semiconducting $\sigma$-Conjugated Systems in Field-Effect Transistors: A Material Odyssey of Organic Electronics. Chem. Rev., 2012, 112, 2208-2267.

6. Baldenebro-Lopez, J.; Castorena-Gonzalez, J.; Flores-Holguín, N.; Almaral Sanchez, J.; Glossman-Mitnik, D.; Density Functional Theory (DFT) Study of Triphenylamine-Based Dyes for Their Use as Sensitizers in Molecular Photovoltaics. Int. J. Mol. Sci., 2012, 13, 4418-4432.

7. Mortimer, R.J.; Electrochromic materials. Chem. Soc. Rev., 1997, 26, 47-156.

8. Kwak, J.; Lyu, Y.Y.; Lee, H.; Choi, B.; Char, K.; Lee, C. New carbazole-based host material for low-voltage and highly efficient red phosphorescent organic light-emitting diodes. J. Mater. Chem., 2012, 22, 6351-6355.

9. Gratzel, M.; Photoelectrochemical cells. Nature., 2001, 414, 338-344.

10. Kappe, C. O.; 100 years of the Biginelli dihydropyrimidine synthesis. Tetrahedron, 1993, 43, 6937-6963.

11. Suman, L. J.; Sweety, S.; Bir. S.; PEGassisted solvent and catalyst free synthesis of 3,4-dihydropyrimidinones under mild reaction conditions. Green Chem., 2007, 9, 740-741. 
12. Gaussian 03, Revision C.02, Gaussian Inc., Wallingford, CT., 2004.

13. Jamroz, M. H.; Vibrational Energy Distribution Analysis: VEDA4 program, Warsaw, Poland, 2004.

14. Michalska, D.; Raint Program, Wroclaw University of Technology, 2003.

15. Michalska, D.; Wysokinski, R.; The prediction of Raman spectra of platinum (II) anticancer drugs by density functional theory. Chem. Phys. Lett., 2005, 403, 211-217.

16. Kuhn, B.; Mohr, P.; Stahl, M.; J. Med. Chem., 2010, 53, 2601-2611.

17. Klein, R. A.; Intramolecular Hydrogen Bonding in Medicinal Chemistry. Chem. Phys. Lett., 2006, 425, 128-133.

18. Russell D. Johnson III (Ed.), NIST Computational Chemistry Comparison and Benchmark Database, NIST Standard Reference Database Number 101, Release 17b, September, 2015.

19. Dhandapani, A.; Manivarman, S.; Subashchandrabose, S.; Saleem, H. Molecular structure and vibrational analysis on (E)-1-(3-methyl-2,6-diphenylpiperidin-4ylidene) semicarbazide. J. Mol. Struct., 2014, 1058, 41-50.

20. Silverstein, M.; Webster, F. X. "Spectrometric identification of organic compounds", sixth edition, John wiley \& sons, Inc, New York, 2001.

21. Socrates, G.; "Infrared and Raman characteristic group wavenumbers table and charts", Third edition, John wiley \& sons, New York, 2001

22. Cinnar, M.; Karaback, M. Determination of conformational and spectroscopic features of ethyl trans-alfa-cyano-3-indole-acrylate compound: An experimental and quantum chemical study. Spectrochim Acta A., 2013, 104, 428-436.

23. Snehalatha, M.; Ravikumar, C.; Hubert joe, I.; Jayakumar, V.S. Vibrational spectra and scaled quantum chemical studies of the structure of Martius yellow sodium salt monohydrate. J. Raman spectrosc., 2009, 40, 1121-1126.

24. Varsanyi, G.; Assignments for Vibrational Spectra of Seven Hundred Benzene Derivatives, Vol. 1 and 2, Academic Kiado: Budapest, 1973.

25. Medhi, K. C.; Barman, R.; Sarma, M. K.
Vibrational spectra, thermodynamic functions and barrier to internal rotation of 2-chloro-5nitropyridine. Indian J. Phys., 1994, 68(2), 189-194.

26. Jamróz, M. H.; Dobrowolski, J. C.; Brzozowski, R.; J. Mol. Struct., 2006, 787, 172-183.

27. Mohan, J.; "Organic Spectroscopy: Principles and Applications", second ed., Narosa Publishing House, New Delhi, 2001.

28. Roeges, N. P. G.; "A Guide to the Complete Interpretation of Infrared Spectra of Organic Structures", Wiley: New York, 1994.

29. Smith, B. C.; "Infrared spectral interpretation: A systematic approach", CRC Press, New York, 1999.

20. Dhandapani, A.; Manivarman, S.; Subashchandrabose, S. Synthesis, single crystal structure, Hirshfeld surface and theoretical investigations on pyrimidine derivative. Chem. Phys. Lett., 2016, 655-656, 17-29.

31. Chithambarathanu, T.; Umayorubagan, V.; Krishnakumar, V.; Vibrational assignments of 2,6-di(p-methoxy phenyl)-3-methyl piperidone, 2,6-di(p-methyl phenyl)-3methylpiperidone, 2,6-di(o-hydroxy phenyl)3-methylpiperidone and 1-methyl-2,6(pmethoxy phenyl) piperidone. Ind. J. Pure Appl. Phys., 2002, 40, 72-74.

32. Reed, A. E.; Weinhold, F.; Natural localized molecular orbitals. J. Chem. Phys., 1985, 83, 1736-1740.

33. Reed, A. E.; Weinstock, R. B.; Weinhold, F.; Natural population analysis. J. Chem. Phys. 1985, 83, 735.

34. Reed, A. E.; Weinhold, F.; Natural bond orbital analysis of near-Hartree-Fock water dimer. J. Chem. Phys., 1983, 78, 4066-4073.

35. Foster, J. P.; Wienhold, F.; Natural hybrid orbitals. J. Am. Chem. Soc., 1980, 102, 7211-7218.

36. Kleinman, D. A.; Nonlinear dielectric polarization in optical media. Phys. Rev., 1962, 126, 1977-1979.

37. Dhandapani, A.; Manivarman, S.; Subashchandrabose, S.; Synthesis, crystal growth, structural evaluation and nonlinear optical analysis of ethyl-4-(3,4dimethoxyphenyl)-6-methyl-2-sulfanylidene3,4-dihydro-1 H-pyrimidine-5-carboxylate J. Mol. Struct., 2017, 1127, 212-225. 